surface. He inquired if the members used ether or chloroform in operating for brain abscess.

Dr. Theobald stated that at the Johns Hopkins Hospital ether was used exclusively.

Dr. BAcon always used ether, as he considered it safer.

\title{
Exhibition of Instruments.
}

Dr. Lewis exhibited three pairs of forceps in which he had modified the jaws respectively in three different ways for aural work-an upturned, a downturned, and a pair the jaws of which opened at an angle of $45^{\circ}$ to the shanks.

Pegler.

\section{Abstracts. \\ MOUTH, Etc.}

Baer, Arthur (Vienna).-On the Recognition of Tuberculosis of the Pharynx. " Monatschrift für Ohrenheilkunde," February, 1899.

Two well-marked cases under the care of Professor von Schroetter are described. The chief complaint was the pain in swallowing, and the diagnosis was made on the typical appearance of the shallow, maplike ulcers, confirmed by the discovery of bacilli in the scraping, though none were found in the sputum. The larynx was in each case unaffected, and in one the lungs to a very slight extent only, but in the other one more extensively. Healing took place under curettement and the application of lactic acid in increasing strength.

\section{Dundas Grant.}

McIntosh, J. W. Persistent Thyro-glossal Duct. "Can. Prac.," June, 1899.

A woman, aged twenty-one, suffering from an enlarged thyroid gland, had for some months complained of an offensive discharge into her throat. At times the discharge was quite profuse. On these occasions she noticed diminution in the size of the goitre. There was no history of abscess; neither was there vomiting, nor coughing, nor accompanying catarrh. Firm compression on the gland produced throat-discharge with diminution of the size of the iniddle lobe. Inunctions of lanolin and iodoform for the time being put an end to the discharge.

Price-Brown.

Petersen.-Demonstration of a Patient with Lichen Ruberplanus on the Mucous Membrane of the Mouth and Palate. "Petersb. Med. Woch.," No. 4, 1899.

The author first put the diagnosis for syphilis. Later on, through 
eruption of lichen ruberplanus on one hand and on the eyelids, it was possible to diagnose the case. The disease is very rare.

R. Sachs.

V. Rosen, H.-Cincommon ('ase of Dangerous Bleeding in consequence of Suallowing "Lecch. "Petersb. Ned. Woch.," No. 10, 1599.

Boy, nine years old, was drinking some water out of a stone jug in the dark, and swallowed a leech. Continuous bleeding from the nose ant throat set in. It was impossible to catch hold of the leech by forceps or any other instrument. Ifter an hour's gargle with permanganate of potash the leech was ejected apparently dead. I. Sachs.

\section{NOSE.}

Birkett, H. S. - Foreign Ijorly in Vaso-pharyn, for Eighteen Years. "Mont. Med. Journ.," Jume, Lis!9.

The patient, a young woman, ared twenty-three, remembered puting a thimble in her mouth when five years old. This was followed by an attack of conghing, when the thimble disappeared. A year later she developed catarrh of the nose, which continued ever afterwards. On examination both nostrils were filled with mucopurulent discharge, and the odour was characteristic of the presence of a foreign body. Post-nasal examination revealed a black mass lying close to the septum, and covered with catarrhal deposit. Under an anisthetic it was removed, and proved to be a tailor's thimble, encrusted with concretions. The surface of the thimble itself was perfectly smooth. Cinder ordinary treatment all the catarrhal and ear symptoms entirely disappeared.

Price-Brown.

Hajek. - Cephalalyia in Diseases of the Nose and its Accessory Cavities. "Wien. Klin. Rundsch." (1899, 22, "Wien. Med. Club.").

Empyema of the accessory cavities of the nose causes cephalalgia in the acute and chronic stages; in acute empyema the cephalalgia is nore neuralgiform, in chronic it is more like diffuse headache. Empyema of the frontal sinus causes more constant cephalalgia; next that of the antrum Highmori. Another peculiarity of the neuralgic pains is that they always come at the same time every day. When these intermittent pains are caused by neuralgia of the supraorbitals there is, according to the experience of the author, always disease of the frontal sinus. Then Ilajek is very sceptical about the cause of cephalalgia through hypertrophy of the nasal mucous membrane; only the hypertrophy of the mucous membrane of the tuberculum septi seems to be an exception. R. Sachs.

Keller (Cologne). - The Connection betueen Disease of the Lachrymal Duct and Rhinology. West German Laryngological and Otological Association, April 16, 1899.

The speaker described first the anatomical, physiological, and pathological conditions, and alluded specially to the mucous valve at the lower end of the lachrymal duct (so called by Husner). Inspiration opens this duct for the evacuation of lachrymation. In the majority of cases, according to Keller, the origin of the lachrymal duct disease is at the nasal opening. 